\title{
POPULATION STRUCTURE AND ECONOMIC CYCLES IN GREECE: A MULTIDIMENSIONAL REGIONAL ANALYSIS (1988-2016)
}

\author{
Luca SALVATI \\ Council for Agricultural Research and Economics (CREA), Arezzo, Italy \\ "Sapienza" University of Rome, Italy
}

\begin{abstract}
Demographic structures have undergone important transformations driven by economic cycles because of population movements and spatially-variable patterns of fertility and mortality. Understanding the latent relationship between changes over time in population structure and sequential waves of expansion and recession is a relevant issue in economic demography. In this regard, the recent history of southern European countries, and especially of Greece, is representative of consecutive economic expansions and recessions. The present study aims at investigating relevant modifications in population structure across Greek regions between 1988 and 2016 using a multi-temporal factor analysis. Being characterized by a relatively young population with traditional family structures, out-migration and moderate immigration up to the late 1980s, Greek demography shifted towards ageing, mononuclear families and a rising immigration rate during the early 2000s economic expansion, with an overall increase of resident population. The subsequent 2007 recession has represented a turning point in Greek demography, consolidating changes in traditional family structures, while stimulating outmigration to northern and western European countries and reducing immigration from developing countries. A diachronic analysis of population structures at sub-national scale indicates a substantial heterogeneity of demographic processes across Greek regions. Metropolitan areas and highly accessible coastal and flat districts including islands experienced rapid population dynamics, while peripheral rural regions underwent a moderate population ageing. Taken together, these processes had a short-term, synergic impact on Greek demographic structure determining a rapid increase in the median population age with possibly negative consequences for the ability of the country's economy to recover from crisis.
\end{abstract}

Key Words: economic crisis, regional demography, multi-temporal factor analysis, Europe.

\section{Introduction}

Long-term development of European countries is the result of a complex interplay between socioeconomic transformations and the underlying demographic trends (Van Nimwegen 2013), at least since the XIXth century (Khan 2008). The so-called demographic transition (DT) has occurred in the 18th century, with a shift from high fertility and mortality rates (and overall young populations), to declining demographic rates and population ageing (Lee 2003), signing "a pathway to change" in the modern industrial societies and economies (Lee and Reher 2011). Lifespan became longer with joint declines in mortality and fertility, and spatially-varying population growth rates (Lee 2003, Blue and Espenshade 2011, Howell et al. 2016). Earlier studies have attempted to ascertain the linkage between demographic dynamics and major economic episodes (Khan 2008, Goldstein et al. 2013), as well as direction and intensity of the causal relationship between socio-demographic and economic changes (Reher 2011). Following Walford and Kurek (2016), DTs reflect a socioeconomic development affecting urban configurations, shaping socio-spatial gradients and altering the distribution of economic functions at the metropolitan scale (Chorianopoulos et al. 2010, 2014, Salvati and Sabbi 2014). Social interactions and their effects on population structure and dynamics have been 
considered in recent studies addressing fertility decline in both advanced and emerging countries (Watkins 1990, Bongaarts and Watkins 1996, Montgomery and Casterline 1996, Behrman et al. 2002).

After a peak of urban concentration around the 1970s - corresponding to the end of the First Demographic Transition - a new demographic wave, defined as the Second Demographic Transition (SDT), has occurred, together with social transformations and demographic redistribution processes at regional scale (Alperovich 1983, Lesthaeghe and van de Kaa 1986, van de Kaa 1987). The SDT gave rise to greater heterogeneity in population dynamics, individual choices about marrying or cohabiting, time of child-bearing, households' size and a widespread population ageing (Billari and Kohler 2004, Haase et al. 2010, Kreyenfeld et al. 2012). Based on SDT outcomes, a new territorial structure, from cities to suburban centres (Bourne 1996, Liu 2005, Kulu et al. 2009), has progressively established in the European countries (Lesthaeghe and Neidert 2006, Caldwell and Schindlmayr 2003, Coleman 2006, 2008, Kalmijn and van Tubergen 2006, Sobotka and Toulemon 2008, Goldstein et al. 2009, Rontos 2007, 2010).

The SDT has interested Southern Europe later than western, central and northern European countries (Council of Europe 2001), with negative rates of population growth prevailing in the region, reaching the minimum level in Greece during the 1990s (Van Nimwegen 2013). Effects of SDT on urban population resulted in the slow transition from compact forms to more polycentric and spatially-balanced settlements (Rontos 2010, Kabisch and Haase 2011, Salvati et al. 2015). Internal and foreign migration plays a major role on demographic changes (Plane 1993, Johnson et al. 2005, Van Criekingen 2010, Blangiardo and Rimoldi 2013, van Bavel and Reher 2013, Taulbut and Robinson 2015). In Greece, internal migration flows were directed to the main urban areas (Athens and, at a lesser pace, Salonika) since the 1950s; conversely, a strong internal migration occurred toward peripheral and rural areas over the last decades, in parallel with a stagnant population growth in central cities, emphasizing new settlement models (Boyle et al. 1998, Sayas 2006, Kasimis 2008, Morelli et al. 2014, Rontos et al. 2016)

Recession is considered a process altering spatio-temporal demographic dynamics, affecting fertility rates (Cherlin et al. 2013, Goldstein et al. 2013, Salvati and Carlucci 2017). Under recession, pro-cyclical fertility trends are explained with economic uncertainty (Hofmann and Hohmeyer 2013), unemployment (Adserà 2004, Vignoli et al. 2012, Tragaki and Bagavos 2014, Cazzola et al. 2016), and forces that influence fertility indirectly such as marriage postponement (Goldstein et al. 2013) or declining marriage rates (Kohler et al. 2002, Billari and Kohler 2004, Kreyenfeld et al. 2012, Lee and Painter 2013). In this regard, the average age of women at marriage and childbearing in Greece, as in other Mediterranean countries, has exceeded the 30 years (Rontos 2007, 2010), in line with what was observed in Western, Central and Northern Europe.

Across Europe, demographic developments contingent on economic pressures are designing a framework of demographic ageing and urban shrinkage, with decreasing growth rates of the working age population, less compensated by migratory flows. These dynamics are prefiguring a risk for regional competitiveness and territorial cohesion due to the inherent spatial variability in the fertility and mortality rates (Rees et al. 2012). Although the country's response to recession depends on specific social, cultural, political and institutional decisions - such as the existence of specific policies to support families and the employment status (Goldstein et al. 2009, Bacci 2012) - the most recent crisis has altered the recovery potential of southern European regions (Bongaarts and Sobotka 2012), because of cuts in public spending which produced a negative influence on social policies (Van Nimwegen 2013).

In Europe, Greece is one of the countries most affected by the recent crisis (Goldstein et al. 2013, Goldstein and Kluge 2016). During the pre-crisis period, especially after the Olympic 
Games (2004), the birth rate and wealth have increased coherently because of the better living conditions (Santow and Bracher 2001, Sobotka et al. 2011), and the contribution of foreign young women that come as immigrants during the 1990s (Lianos 2001, Rovolis and Tragaki 2006, Maloutas 2007, Goldstein et al. 2009). Unemployment rates have increased rapidly during the last recession, while the gross domestic product dropped significantly (Grigoriadis and Salvati 2015). On the purely demographic side, the trend of rising births in the pre-crisis period (from 100643 in 1999 to 118302 in 2008) experienced a drastic reversal, with births decreasing by nearly $15 \%$ between 2008 and 2012 (Horton 2009, Vrachnis et al. 2014). If current fertility oscillations are related to socioeconomic conditions largely variable over space (Martín-García 2013), the need for social and family policies may influence the actual situation of the (future) parents (McDonald 2006, Gauthier 2007). Current research indicated that the role of the state supporting decisions such as marriage or childbearing is of statistical significance in contemporary Greece (Rontos 2007).

Based on these premises, the present study aims to investigate the Greek demographic changes testing for short-term recessional impact on regional demographic structures. Greece is regarded as a paradigmatic case for studying the impact of economic crisis on population dynamics, deriving from migration, suburbanization, and long-term socioeconomic transformations. Featuring intermediate conditions between advanced and emerging countries (Carlucci et al. 2017), the Greek context may provide insights on demographic studies contributing to policy analysis (Salvati and Morelli 2014). In the face of a gloomy prospective scenario of shrinking active population and increasing territorial disparities, European countries are increasingly required to develop effective policy aiming to foster regional demographic resilience to the on-going economic crisis.

\section{Methodology}

\section{Study area}

This study investigates the population structure and the related demographic variables in 13 Greek administrative regions ('periferias') corresponding to the NUTS-2 level of the European Union Territorial Statistical classification adopted by Eurostat. Among these regions, two of them can be considered as 'metropolitan', with urban settlements prevailing on rural areas (Attica and Central Macedonia, respectively hosting Athens and Salonika, the largest cities in Greece, concentrating together nearly $50 \%$ of the country's population); two regions can be regarded as mixed 'urban-rural' areas (Thessalia and Kriti, hosting large cities such as Larissa, Volos, Iraklio and Chanià); three as 'tourism-oriented' coastal areas including islands (lonia Nissia, Notio Aegeo, Vorio Aegeo); two as rural-accessible areas (Peloponnisos and Sterea Ellada hosting head towns such as Patras and Lamia); and the last four as rural, peripheral regions (Ipeiros, Dytiki Ellada, Dytiki Makedonia, Anatoliki Makedonia-Traki).

\section{Demographic data}

Data were derived from the national population register held by the Hellenic Statistical Authority (ELSTAT). Long-term demographic trajectories were assessed using homogeneous time series at regional scale available since 1988 and considering the age population structure (7 classes: $0-14,15-19,20-24,25-29,30-44,45-64,65+$ years; total and by sex), citizenship (native Greeks, European Union, extra-European) and marital status (single, married, divorced and widowers). Thus, a total of 21 indicators were computed: (i-vii) percent share of population by age class in total population ('0-14\%', '15-19\%', '20-24\%', '25-29\%', '30-44\%', '45-64\%', '65+\%'), (viii) elderly index ('Eld'), (ix) male-to-female ratio ('MtoF'), (x-xvi) male-to-female ratio by age class ('MtoF0-14', 'MtoF15-19', 'MtoF20-24', 'MtoF25-29', 'MtoF30-44', 'MtoF45-64', 'MtoF65+'), (xvii-xviii) percentages of (non-Greek) European Union citizens ('EU\%') and nonEuropean citizens ('Abroad') in total population, (xix-xx) percentage of single ('Single') and 
married ('Married') people in total population and, finally, (xxi) percentage of regional population in total country population. Percentages of native Greeks and divorced people (or widowers) in total population were not included in the statistical analysis to avoid multicollinearity.

\section{Statistical analysis}

A preliminary outlook of long-term population trends in Greece was derived from a descriptive analysis of the indicators described in section 2.2 by year. This analytical framework was enriched with a spatio-temporal analysis of population growth rates in the 13 Greek administrative regions using 4-years time windows partitioning the study period into 7 homogeneous intervals (1988-1992, 1992-1996, 1996-2000, 2000-2004, 2004-2008, 20082012, 2012-2016). A Principal Component Analysis (PCA) was run on the data matrix mentioned above with the aim to extract the two most relevant axes and plotting indicators loadings and regions' scores (years from 1988 to 2016). PCA enables a meaningful data exploration by summarizing large tables of statistical data into few latent (and understandable) dimensions based on a restricted number of key variables, obtaining a comprehensive outlook of the main demographic patterns observed over time and space in Greece (Salvati and Carlucci 2017). A hierarchical clustering was finally run on the whole data matrix (standardized data) using Euclidean distances and the Ward's agglomeration rule for two distinct years (1988 and 2016) representing the beginning and the end of the study period. The cluster analysis ordered data in a hierarchical sequence through a dendrogram, identifying regions with homogeneous demographic characteristics (Pili et al. 2017).

\section{Analysis of long-term demographic trajectories in Greek regions}

A Multiway Factor Analysis (MFA) was finally applied to the 21 demographic indicators observed at each time point $(1988,1992,1996,2000,2004,2008,2012,2016)$ for every administrative region with the aim to identify specific demographic trajectories at the regional level in Greece. The multiway data analysis, a generalization of the PCA, identifies complex structures in higher-order datasets, where data have three or more dimensions (Kroonenberg 2008). The MFA constitutes of four distinct steps: (i) comparing (and analyzing the relationship between) data sets over time; (ii) combining them into a common multivariate structure called 'compromise', (iii) analysing the 'compromise' data matrix to reveal the common structure between the observations and, finally, (iv) projecting each of the original data sets into the compromise to analyze communalities and discrepancies (Coppi and Bolasco 1988). Absolute eigenvalues $>1$ define relevant factors, i.e. factors extracting a proportion of variance not less than the original variables (Zambon et al. 2018). By linking variables with coherent spatiotemporal patterns represented by the few factors that explain a large proportion of variance, the MFA provides an indirect measure of redundancy among demographic indicators. Based on a joint analysis of changes in all dimensions considered (21 indicators, 13 administrative regions, 8 points in time), the MFA allows evaluating if the position of each variable (or region) is stable or variable over time by projecting them into a biplot illustrating the same multivariate factor plane.

\section{Results}

\section{Spatio-temporal changes in the structure of Greek population}

Following a continuous population increase up to 2009 (11.061 million inhabitants) and a subsequent decline by nearly 300 thousand inhabitants along the last 7 years, the demographic structure in Greece changed during the study period resulting in a progressively elder population (Table 1). The mean population age for the whole of Greece increased from 36.8 years in 1988 to 41.9 in 2016 . The share of children aged $0-14$ years in the total 
population declined from $20.4 \%$ (1988) to $14.6 \%(2016)$ and the reverse pattern was observed for the population aged $65+$ years (from $13.8 \%$ in 1988 to $21.1 \%$ ). Male-to-female ratio increased moderately over time between 1988 (92.9) to 2000 (96.4), decreasing slowly in the most recent time period to 94.8 in 2016 . Non-Greek inhabitants increased progressively during the study period amounting to $5.2 \%$ of the total population in 2016 . Inhabitants born in a European Union country (excluding Greece) increased from $0.1 \%$ in 1988 to $1.3 \%$ in 2009 2012, declining slowly to $0.9 \%$ in 2016 . The same temporal pattern, although with higher percent values, was observed for inhabitants born in a non-European country, increasing from $0.5 \%$ in 1988 to $6.4 \%$ in 2012 , and subsequently decreasing to $4.3 \%$ in 2016 as a consequence of economic crisis. The analysis of marital status in Greece indicates a continuous decline in the number of married people since 1997 (when the highest value of the available time series was observed: 53.7\%), reaching the lowest values in 2015 and 2016 (49\%). Singles showed a less defined temporal patterns, with relatively similar values observed at the beginning and the end of the study period $(38.7 \%$ in 1988 and $39.2 \%$ in 2016) and the highest figure recorded in 2003 (40.2\%). A PCA biplot was used to summarize the most relevant changes in the Greek population structure of the 1988-2016 period (Fig. 1). Components 1 and $2(60.9 \%$ and $21.5 \%$ of total variance) aggregate demographic indicators with similar temporal patterns, distinguishing three time intervals along component 1: (i) years between 1988 and 1997 (clustered along the negative side of component 1 associated to a relatively young demographic structure, (ii) a transitional period constituted by three years (1998, 1999 and 2000) characterized by the highest incidence of population aged 20-24 and (iii) a more recent, heterogeneous time interval including the years from 2001 to 2016, separated in two groups along component 2: (a) the years from 2001 to 2008, associated to a population structure characterized by the dominance of working age classes (25-64 years) and migrants from extra-European countries and (b) the years from 2009 to 2016, outlining a process of population ageing, with reduced migration rates possibly driven by the 2007-2008 recession.

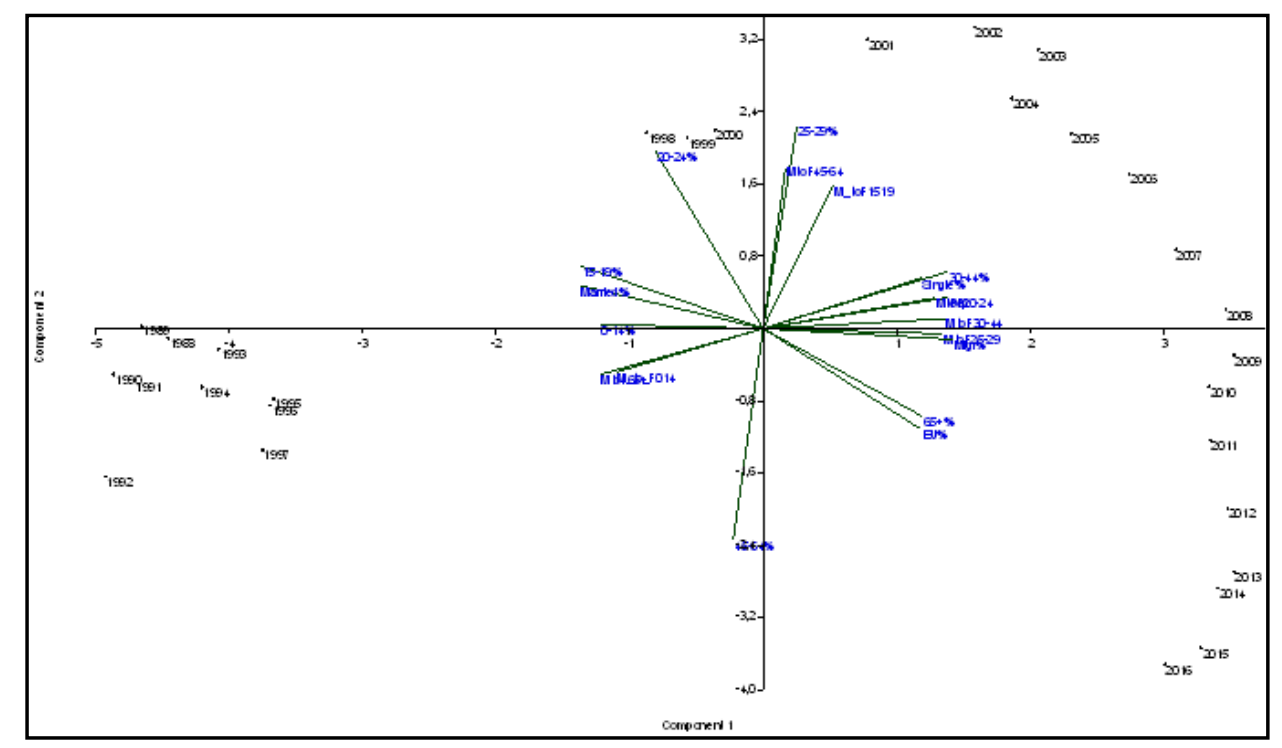

Fig. 1 - The Principal Component Analysis biplot illustrating the evolution of population structure in Greece, 1988-2016 (see Table 1 for time series indicators) 
Trends over time in population structure of Greece, selected years (1988-2016)

\begin{tabular}{|c|c|c|c|c|c|c|c|c|c|c|c|c|c|c|}
\hline \multirow{2}{*}{ Year } & \multirow{2}{*}{\begin{tabular}{|c}
$\begin{array}{c}\text { Populati } \\
\text { on }\end{array}$ \\
$\begin{array}{c}(1000 \\
\text { inh. })\end{array}$ \\
\end{tabular}} & \multirow{2}{*}{$\begin{array}{l}\text { Elderly } \\
\text { index } \\
\end{array}$} & \multicolumn{7}{|c|}{ Age structure (\% class, yrs.) } & \multirow{2}{*}{$\begin{array}{c}\begin{array}{c}\text { Male } \\
\text { to }\end{array} \\
\begin{array}{l}\text { Fem. } \\
\text { ratio }\end{array} \\
\end{array}$} & \multicolumn{2}{|c|}{ Citizenship (\%) } & \multicolumn{2}{|c|}{$\begin{array}{c}\text { Marital } \\
\text { status (\%) }\end{array}$} \\
\hline & & & $0-14$ & $\begin{array}{l}15- \\
19 \\
\end{array}$ & $\begin{array}{l}20- \\
24 \\
\end{array}$ & $\begin{array}{l}25- \\
29 \\
\end{array}$ & $\begin{array}{l}30- \\
44 \\
\end{array}$ & $\begin{array}{l}45- \\
64 \\
\end{array}$ & $65+$ & & EU & Abroad & $\begin{array}{l}\text { Sin- } \\
\text { gle }\end{array}$ & $\begin{array}{l}\text { Mar- } \\
\text { ried }\end{array}$ \\
\hline 1988 & 9739 & 36.8 & 20.4 & 7.2 & 6.3 & 6.5 & 20.3 & 25.6 & 13.8 & 92.9 & 0.1 & 0.5 & 38.7 & 53.2 \\
\hline 1992 & 9943 & 38.4 & 17.4 & 7.3 & 6.6 & 6.2 & 20.1 & 26.5 & 15.8 & 94.0 & 0.2 & 0.9 & 37.6 & 53.7 \\
\hline 1996 & 10254 & 39.4 & 15.9 & 7.1 & 6.3 & 6.8 & 20.5 & 25.5 & 17.8 & 92.7 & 0.1 & 1.2 & 37.0 & 53.6 \\
\hline 2000 & 10472 & 39.0 & 15.6 & 7.0 & 6.9 & 7.5 & 22.1 & 24.1 & 16.8 & 96.4 & 0.2 & 2.6 & 39.6 & 51.6 \\
\hline 2004 & 10925 & 39.6 & 15.0 & 5.8 & 6.9 & 7.5 & 22.6 & 24.0 & 18.2 & 95.9 & 0.6 & 4.6 & 38.6 & 51.9 \\
\hline 2008 & 11059 & 40.3 & 14.7 & 5.4 & 5.8 & 7.3 & 23.0 & 25.0 & 18.7 & 95.6 & 1.2 & 5.3 & 40.0 & 50.4 \\
\hline 2012 & 10967 & 41.1 & 14.8 & 5.2 & 5.1 & 6.4 & 22.7 & 25.9 & 20.0 & 94.9 & 1.3 & 5.7 & 39.8 & 49.7 \\
\hline 2016 & 10783 & 41.9 & 14.6 & 5.0 & 4.9 & 5.6 & 21.7 & 27.2 & 21.1 & 94.8 & 0.9 & 4.3 & 39.2 & 49.3 \\
\hline
\end{tabular}

\section{Population growth in Greek regions}

Greek regions presented different demographic structures resulting in spatially-heterogeneous rates of population growth during the study period (Table 2). Four regions totalized a negative rate of population growth in the first time period (1988-1992). Results for time intervals until 2008 have identified a period of demographic stability, with moderate (and spatiallyhomogeneous) changes in the regional population structures. Starting from 2008, the number of Greek regions totalizing a negative population growth increased to 6 in 2008-2012 and to 13 out of 13 in 2012-2016. Consequently, the population grew in the whole of Greece from 1988 to 2009, declining moderately in the following period. Population decline was likely the most relevant demographic change along the crisis' period, affecting (more or less) markedly the Greek regional population structure.

Table 2

Annual population growth rate (\%) in Greek administrative regions by 4-year time interval, 1988-2016

\begin{tabular}{|l|c|c|c|c|c|c|c|}
\hline Year & $1988-1992$ & $1992-1996$ & $1996-2000$ & $2000-2004$ & $2004-2008$ & $2008-2012$ & $2012-2016$ \\
\hline $\begin{array}{l}\text { Anat. Makedonia- } \\
\text { Thraki }\end{array}$ & 0.15 & 0.72 & 0.45 & 0.74 & 0.21 & 0.40 & -0.43 \\
\hline Attiki & 1.66 & 0.06 & 0.00 & 0.40 & 0.33 & -0.54 & -0.63 \\
\hline Dytiki Ellada & -1.00 & -0.71 & 4.59 & 0.11 & -0.11 & -0.65 & -0.32 \\
\hline Dytiki Makedonia & 1.21 & 3.10 & -0.60 & 0.32 & -0.19 & -0.37 & -0.59 \\
\hline Ionia Nissia & -0.06 & -0.62 & 3.50 & -0.12 & 0.32 & 0.13 & -0.33 \\
\hline Ipeiros & -2.11 & 1.46 & 3.60 & 1.09 & 0.14 & -0.01 & -0.41 \\
\hline Kentriki Makedonia & 0.57 & 1.97 & 0.24 & 1.01 & 0.44 & -0.28 & -0.25 \\
\hline Kriti & -0.51 & 3.29 & 3.50 & 1.35 & 0.81 & 0.30 & -0.02 \\
\hline Notio Aigaio & 1.27 & 0.80 & 3.15 & 3.03 & 0.94 & 1.20 & -0.47 \\
\hline Peloponnisos & 0.76 & 1.12 & 1.52 & -1.33 & 0.19 & 0.08 & -0.23 \\
\hline Sterea Ellada & -1.24 & 0.90 & 3.55 & 0.18 & 0.25 & 0.24 & -0.26 \\
\hline Thessalia & -0.63 & 0.95 & 0.98 & 0.69 & 0.16 & -0.28 & -0.31 \\
\hline Voreio Aigaio & -2.12 & -0.37 & 1.65 & 0.61 & -0.18 & 0.72 & -0.71 \\
\hline
\end{tabular}

Components 1 and 2 (74.3\% and $13.7 \%$ of total variance) aggregate demographic indicators with similar time patterns (Fig. 2), distinguishing 5 time intervals along both components: (i) years between 1988 and 1991 (clustered along the negative side of components 1 and 2), 
negatively associated to urban regions, such as Attica and central Macedonia (respectively with Athens and Salonika as head cities), and to some rural regions including Peloponnese and western Macedonia; (ii) years between 1993 and 1997, connected with the previous cluster by an intermediate point representing year 1992 and clustered along the negative and positive sides respectively of components 1 and 2; (iii) years between 1998 and 2000, clustering along the positive and negative sides respectively of components 1 and 2 and being associated with rural regions such as western Greece, central Greece and northern Aegean Islands; (iv) years between 2001 and 2010, clustered along the negative side of both components 1 and 2 and strongly correlated with tourism-specialized regions such as Crete and southern Aegean Islands, and finally (v) years between 2012 and 2016, connected to the previous group by an intermediate year 2012, and clustered along the positive and negative sides respectively of components 1 and 2 . Taken together, component 1 represents the varying intensity of population growth over time and component 2 indicates the regional differentiation in population structures across Greece, separating the high-density areas (such as Attica and central Macedonia) from the low-density areas such as western Greece and northern Aegean Islands.

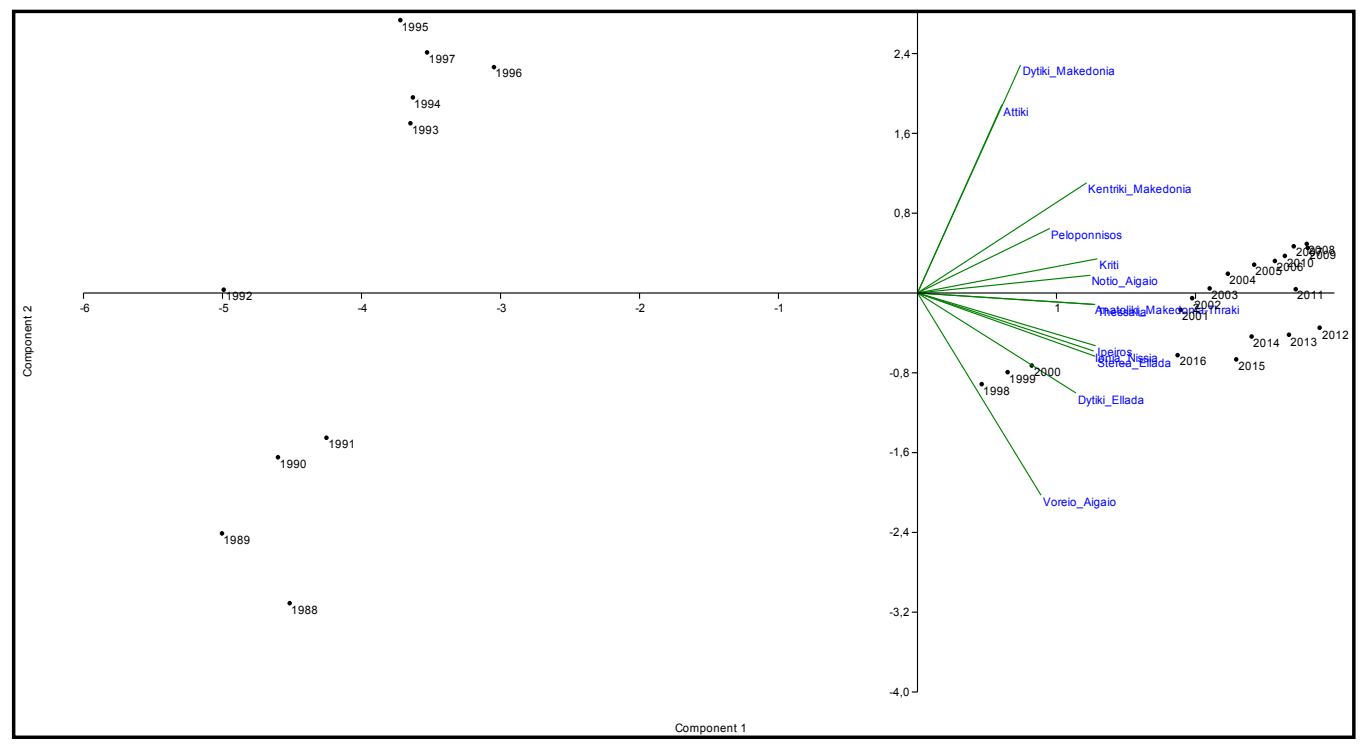

Fig. 2 - Principal Component Analysis biplot illustrating population growth in Greece, 1988-2016

(see Table 2 for time series indicators)

\section{Hierarchical clustering of population structure in Greek regions}

Fig. 3 illustrates the results of a cluster analysis assessing similarities among Greek regions in terms of population structure at the beginning (1988) and the end (2016) of the study period. The 1988 dendrogram separated urban regions (Attica and central Macedonia) from tourismspecialized regions (Thessalia, Ionian Islands, and Northern Aegean Islands), accessible rural regions (Crete, western Macedonia and Sterea Ellada) and more peripheral rural regions (Ipiros, Eastern Macedonia and Trace, western Greece, southern Aegean Islands and Peloponnese). The 2016 dendrogram indicates a different spatial configuration evidencing a subtle geographical gradient distinguishing highly-populated regions from more remote and rural regions. Regions with medium-high population density clustered together (central 

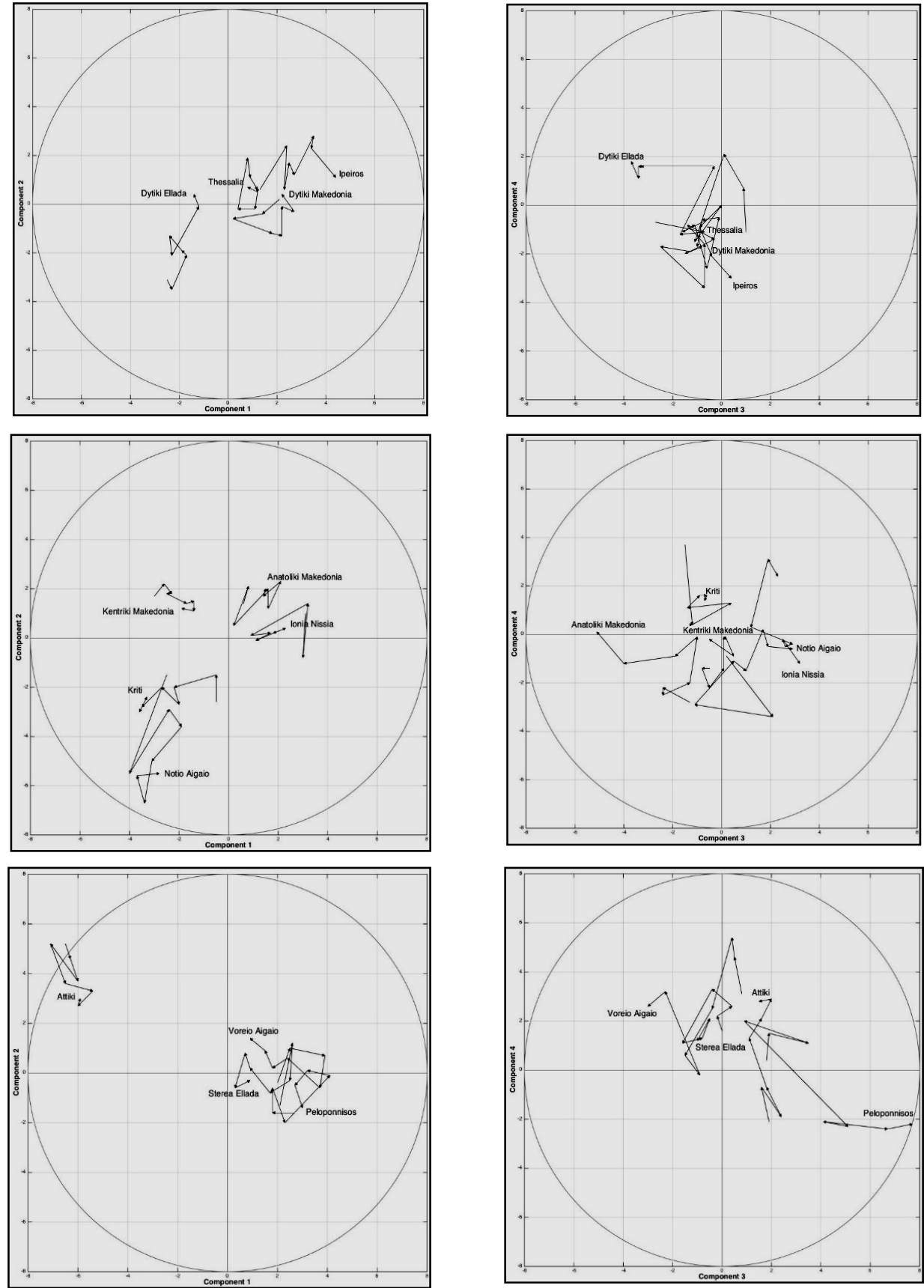

Fig. 3 - Results of a Multiway Factor Analysis applied to population structure indicators in Greek regions (1988-2016) by 4-years' time interval (selected variable's trajectories in each plot) 
Macedonia, Crete, Thessalia, southern Aegean Islands and western Macedonia); however, Attica was grouped with northern Aegean Islands in another cluster. The discrimination in accessible and remote rural regions was less evident in 2016 than in 1988, evidencing only some dynamic areas of the country (Peloponnese, Ionian Islands, Ipiros) and some remote districts (central Greece, Eastern Macedonia and Trace, western Greece).

\section{Multiway Factor Analysis}

MFA extracted 4 significant components explaining $68.7 \%$ of the total matrix variance (Table $3)$. Factor $1(30.3 \%)$ represented a typical ageing gradient opposing elder population segments and married people (positive loadings) to young population segments (negative loadings) in turn associated with non-EU citizens, singles and higher values of the regional population size. This indicates that regions with the highest absolute population (Attica, central Macedonia, Crete, Thessalia) are those with the youngest and most dynamic population structure. Factor 1 loading structure was relatively stable over time opposing young and old population classes in more recent years, too. In 2016, the male-to-female ratio of the population class $45-64$ years was associated positively with component 1 , being higher in regions experiencing more rapid ageing processes. Factor 2 (17.4\%) opposed regions with a population structure dominated by young population segments from those dominated by population segments in working ages. The structure of factor loadings changed over time, illustrating a geographical gradient associated with the migrant population and the male-to-female ratio for age class $65+$ years (negative score) and the absolute population size (positive score). Factor $3(13.1 \%)$ was relatively depolarized in 1988 (attributing positive loadings only to the young population segment), being relatively more structured in 2016 and separating a working age population class between 45 and 64 years (positive loadings) from students and young workers (from 15 to 24 years, receiving negative loadings). Non-Greek native citizens (both from other European

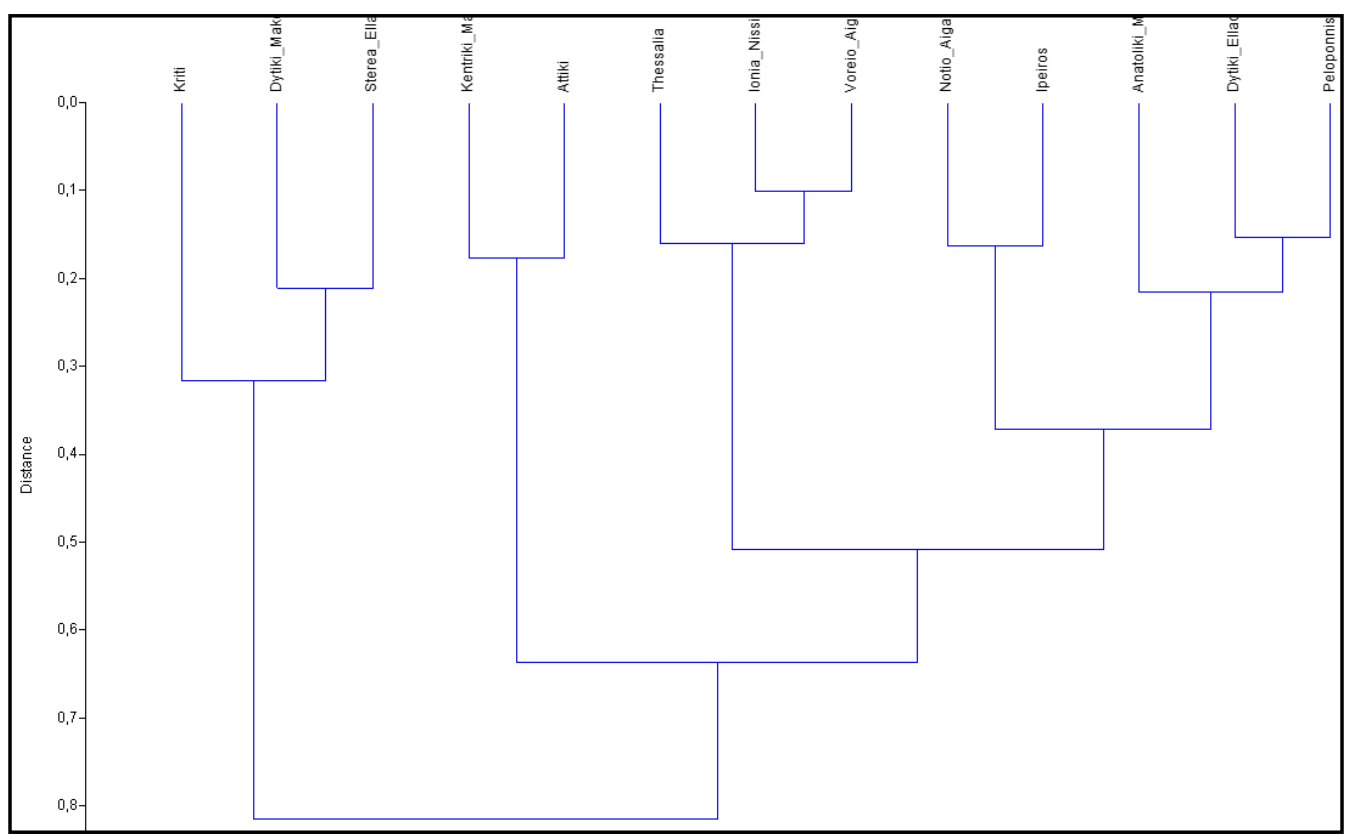

Fig. 4 - Hierarchical clustering (Euclidean distances, Ward's agglomeration rule) assessing similarity in regional population structures in Greece

(dendogram : 1988) 


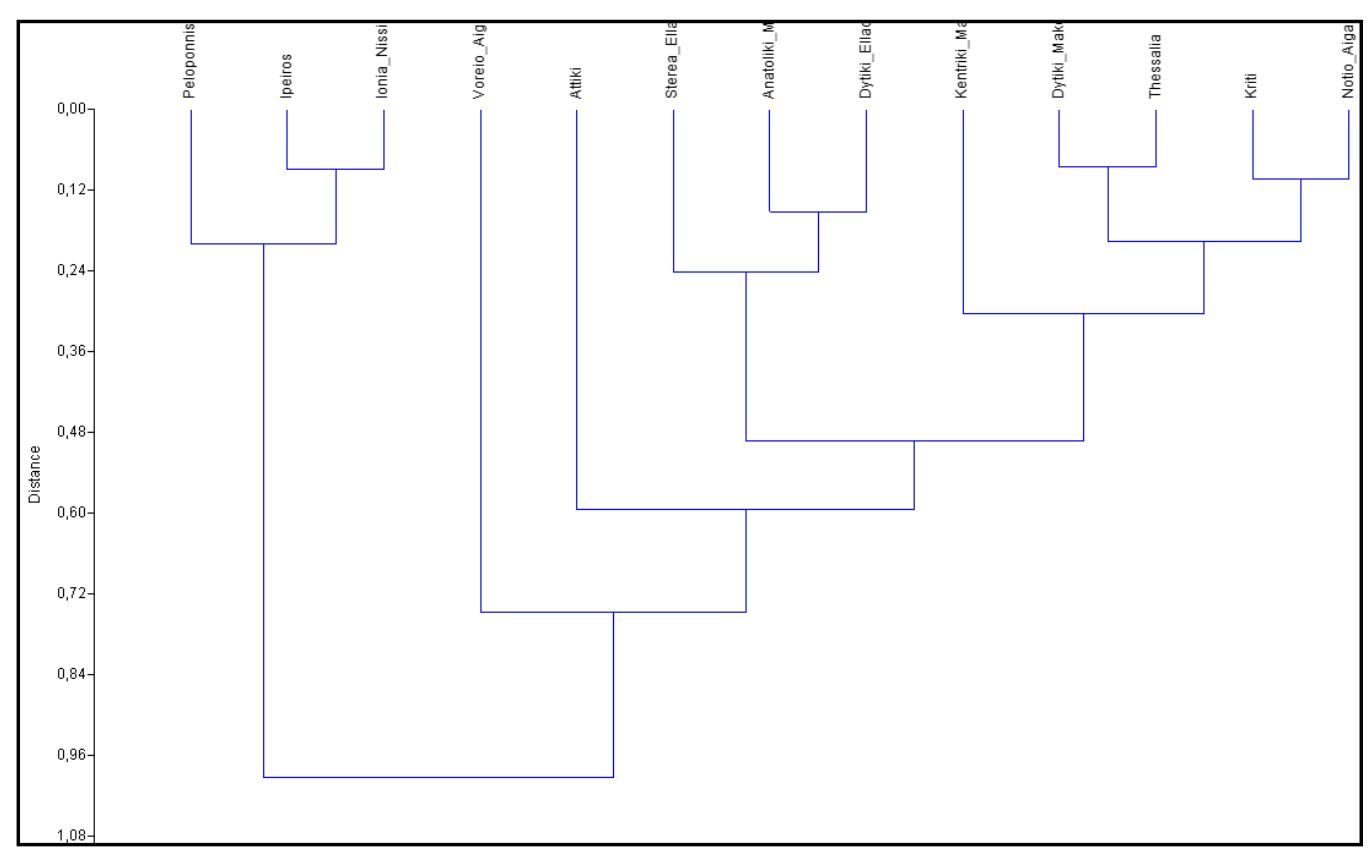

Fig. 4 - Hierarchical clustering (Euclidean distances, Ward's agglomeration rule) assessing similarity in regional population structures in Greece

(dendogram : 2016)

countries and from extra-European countries) were positively associated with the working age population class (positive loadings). Finally, Factor $4(7.9 \%)$ illustrated a latent gradient characterized by spatio-temporal changes in male-to-female ratios by age class. Regional trajectories resulting from MFA (Fig. 4) confirm the insights on the evolving demographic structures provided by the previous analysis, highlighting the comparative advantages of urban regions (Attica, central Macedonia) first (1988-1997) and of tourism-specialized regions (Crete and southern Aegean Islands), especially during the crisis (2010-2016).

\section{Discussion}

Demographic indicators are suitable tools to identify and characterize spatial and temporal mechanisms behind the intrinsic linkages between population processes and economic dynamics (Watkins 1990, Chelli and Rosti 2002, Sobotka et al. 2011, Costa 2013, Matthews and Parker 2013, Van Nimwegen 2013). A spatio-temporal analysis of demographic patterns allowed a comprehensive characterization of short and long-term socioeconomic dynamics across the urban-rural gradient in Greece. Our results show a complex geography of demographic dynamics reflective of the multiple relationships between population distribution, socio-spatial structure and economic determinants. Urban areas with an economic structure centred on traditional and advanced services were characterized by anticipated (and possibly accelerated) demographic dynamics than rural areas with an economic structure centred on agriculture and traditional industrial sectors (e.g. manufacturing, construction). For example, dynamics leading to population aging were usually more rapid in metropolitan regions (Attica, central Macedonia) than in neighbouring rural regions. A mixed demographic pattern was characteristic of coastal and highly accessible rural regions with an economic base oriented toward tourism, commerce and construction. The impact of economic expansion and recession 
on demographic dynamics was different in these three regional typologies, suggesting the role of different territorial, social, institutional and cultural factors.

Table 3

Variable's loadings of a Multiway Factor Analysis run on demographic indicators in Greek regions, selected years (bold indicates loadings $>0.5$ )

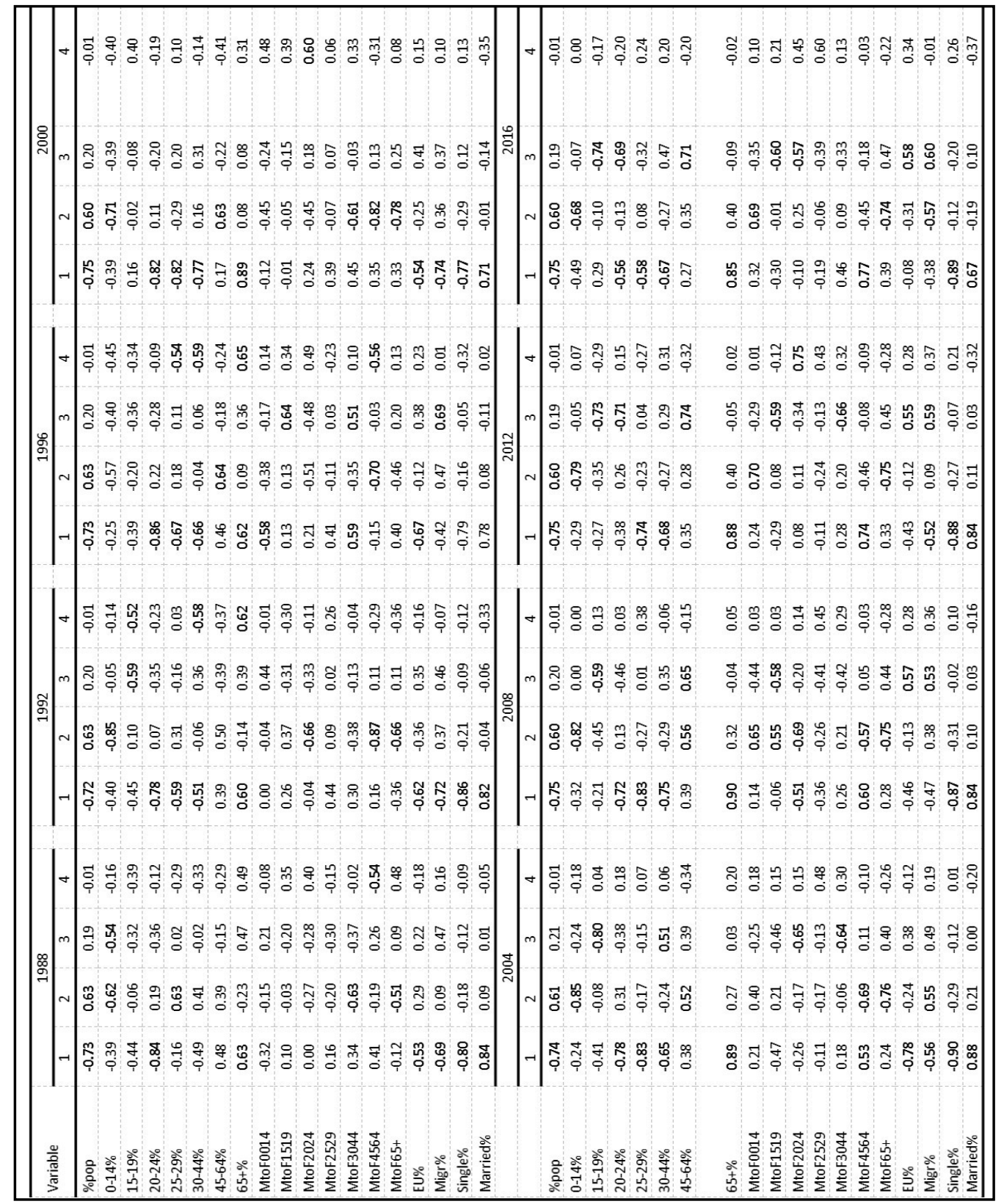


More specifically, the empirical results of our study evidenced a strong demographic variability over time and space, demonstrating that during economic expansions, population increased especially in metropolitan regions, in line with new residential migration processes (Arapoglou 2006, Arapoglou and Sayas 2009). As illustrated by hierarchical clustering, evidences for a second demographic transition in Greece were reflective of (more or less rapid) transformations in social life, urban/rural structures (e.g. land prices, local labour markets, population density, industrial concentration), a progressive decline in fertility rate and modifications in the structure of the 'traditional' family (Buzar et al. 2007, Gavalas et al. 2014), with a pivotal role played by suburbanization (Delladetsima 2006, Kroll and Kabisch 2012, Cuadrado-Ciuraneta et al. 2017).

The final outcomes of the Multiway Factor Analysis indicate that short- and medium-term demographic dynamics were largely sensitive to economic conditions in Greece, as observed elsewhere in Europe (Sobotka et al. 2011, Walford and Kurek 2016). In this regards, the 2007 recession has catalyzed a strong interest on issues regarding economic instability and population/family changes (Kreyenfeld et al. 2012, Neels et al. 2013). Despite a recovery in fertility rates related to declining unemployment rates during the pre-crisis period (Remoundou et al. 2016), all the European countries have witnessed a reduced fertility rate since 2008 (Walford and Kurek 2016). For instance, as stated by Goldstein et al. (2013), the positive trend in Greek fertility rate has stopped in 2009 , when the Greek economy started to falter. The economic crisis has mainly affected the most vulnerable social classes (Gkartios 2013, Gkartios and Scott 2015). In this sense, negative economic conditions have adversely affected the formation of new households (Sobotka et al. 2011, Goldstein et al. 2013, Walford and Kurek 2016). Birth rates declined in economically-disadvantaged districts, including some urban zones, while increasing in wealthy and more accessible areas of the country. This outcome exacerbated a latent polarization in the economically advanced and deprived areas (Salvati et al. 2016)

The contribution of our research findings to the existing knowledge lies in the identification of a close relationship between demography and economic cycles in Greece, which can be better understood through a spatio-temporal analysis of population dynamics along the urban-rural gradient (Kroll and Kabisch 2012, Serra et al. 2014, Di Feliciantonio and Salvati 2015). Greek demographic changes in recent time periods exposed regional population structures to a significant impact of economic recession. As one of the most affected European countries by the 2007 recession, population dynamics can influence and, in turn, be affected by other social processes, including migration, suburbanization and economic transformations based e.g. on technological advancements and globalization (Rontos et al. 2016). By evidencing transitional conditions typical of Mediterranean countries (Golini et al. 2014), the Greek case provides insights on demographic studies and policy analysis. A comprehensive knowledge of the most recent spatial demographic trends may help designing better development and social policies adapting to economic restrictions, decrease of personal incomes and cuts in public spending (Dijkstra et al. 2015).

In face of a gloomy scenario of shrinking active population and growing territorial disparities, European countries are increasingly required to develop effective policies aiming to foster regional resilience to the on-going economic crisis. A spatial and temporal analysis through population statistics ensures the comparison of areas with different demographic patterns in the same country over a long-time interval (Kabisch and Haase 2011). Using a multivariate approach focused on vital statistics, the present study illustrated recent socioeconomic transformations in a southern European country under recession (Zambon et al. 2017, 2018), indicating how migration, economic crisis and the underlying demographic transition have shaped the current demographic profile of Greek regions. In this regard, demographic indicators allow a joint analysis of spatial, population and settlement structures at regional scale. 
Implementation of effective socioeconomic policies is moulded by an incomplete understanding of the interplay between demographic factors, social forces and drivers of local development. Taken together, the results of our study contribute to design scale-dependent policies reducing social inequalities and contrasting demographic and economic polarizations. In this regard, multiple factors at the base of population growth and demographic change in local districts need specific monitoring efforts based on place-specific indicators and geographic information systems supporting decision-making, planning measures and developmental policies. In particular, understanding local-scale fertility and demographic trends, in both direction and intensity, seems to be an essential information base to design and implement policy measures stimulating a post-crisis recovery of local contexts affected by important demographic imbalances or in a condition of economic marginality. Policies addressing local-scale social issues and economic dimensions (e.g. oriented along the urban-rural gradient) are also particularly effective in poverty alleviation and socio-spatial rebalancing.

\section{Conclusions}

The present study illustrates an original methodology evidencing socio-demographic transformations associated with economic cycles, population movements and varying fertility and mortality patterns in a representative country of Southern Europe. Understanding the intrinsic relationship between demographic change and economic cycles requires further research comparing the impact of economic cycles, policy decisions and social evolution on local-scale demographic structures across countries and regions. Our study finally emphasizes the need to integrate different issues together (e.g. economic geography, territorial planning, urban-rural problems), offering a multi-disciplinary vision of socioeconomic contexts rapidly evolving over time.

Although qualified information about population dynamics contribute to understanding multi-faceted dimensions of regional demographic patterns under different economic cycles, further research is required to increase the reliability of the proposed operational framework, technical accuracy and standardization, allowing comparability among empirical studies and applicability in other research contexts or territorial conditions. Formulation of new indicators evaluating the impact of short-term recessionary shocks on the population dynamics at various spatial scales appears as a relevant issue for future methodological research in the field of official statistics and regional demography. Moreover, approaches based on exploratory data analyses may present some weaknesses when applied to complex socioeconomic phenomena. Although multi-dimensional techniques help identifying apparent (and latent) factors reflective of the inherent complexity of socioeconomic local systems, limitations to this approach depend on the fact that ordination and similarity analysis as well as correlation patterns do not necessarily imply causative processes.

In this regard, time series frameworks (based on both deterministic and stochastic approaches) can provide additional evidences that reveal changes in long-term structures of demographic indicators. More specifically, regionalized time series approaches may identify and characterize spatial patterns in the population dynamics specifically influenced by endogenous and/or exogenous forces. Spatial econometric procedures can also identify significant relationships between demographic patterns and socioeconomic factors characterizing the background regional context rapidly transforming under economic cycles. Qualitative techniques such as Delphi methods, focus groups, in-depth interviews to stakeholders and key experts may refine knowledge on complex demographic systems derived from the use of strictly quantitative approaches. A qualitative approach based on one or more case studies is especially suited to shed more light on short-term demographic dynamics (e.g. driven by a persistent economic stagnation), complementing a basic knowledge of long-term dynamics derived from a quantitative analysis of statistical indicators covering large areas, from administrative regions 
up to the whole of countries. The reliability of approaches integrating quantitative and qualitative procedures can be finally verified comparing the results obtained at different spatial scales, from regional (e.g. prefectures) to local (e.g. municipal) levels.

\section{References}

ADSERÀ A. (2004), Changing fertility rates in developed countries. The impact of labor market institutions, Journal of Population Economics 17 (1), 17-43.

ALPEROVICH G. (1983), An empirical study of population density gradients and their determinants, Journal of Regional Science 23 (4), 529-540.

ARAPOGLOU V. P. (2006), Immigration, segregation and urban development in Athens: the relevance of the $L A$ debate for Southern European metropolises, The Greek Review of Social Research 121(C), 11-38.

ARAPOGLOU V. P., SAYAS J. (2009), New facets of urban segregation in southern Europe. Gender, migration and social class change in Athens, European Urban and Regional Studies 16 (4), 345-362.

BACCI M. L. (2012), Low fertility in historical perspective, Population and Development Review 38 (Supplement), 72-82.

BEHRMAN J. R., KOHLER H.-P., WATKINS S. C. (2002), Social networks and changes in contraceptive use over time: Evidence from a longitudinal study in rural Kenya, Demography 39 (4), 713-738.

BILLARI F., KOHLER H.-P. (2004), Patterns of low and lowest-low fertility in Europe, Population Studies 58 (2), 161-176.

BLANGIARDO G. C., RIMOLDI S. M. L. (2013), The potential demography: a tool for evaluating differences among countries in the European Union, Genus 68 (3), 63-81.

BLUE L., ESPENSHADE T. J. (2011), Population momentum across the demographic transition, Population and Development Review 37 (4), 721-747. BONGAARTS J., SOBOTKA T. (2012), A demographic explanation for the recent rise in European fertility, Population and Development Review 38 (1), 83-120.

BONGAARTS J., WATKINS S. C. (1996), Social interactions and contemporary fertility transitions, Population and Development Review 22 (4), 639-682. BOURNE L. S. (1996), Reinventing the suburbs: Old myths and new realities, Progress in Planning 46 (3), $163 \square 184$.

BOYLE P., HALFACREE K. H., ROBINSON V. (1998), Exploring Contemporary Migration, Longman, Essex.

BUZAR S., OGDEN P., HALL R., HAASE A., KABISCH S., STEINFIIHRER A. (2007), Splintering urban populations: emergent landscapes of reurbanisation in four European cities, Urban Studies 44 (4), 651-677.

CALDWELL J. C., SCHINDLMAYR T. (2003), Explanations of the fertility crisis in modern societies: a search for commonalities, Population Studies 57 (3), 241-263. CARLUCCI M., GRIGORIADIS E., RONTOS K., SALVATI L. (2017), Revisiting a Hegemonic Concept: Long-term 'Mediterranean Urbanization' in between city re-polarization and metropolitan decline, Applied Spatial Analysis and Policy 10 (3), 347-362.

CAZZOLA A., PASQUINI L., ANGELI A. (2016), The relationship between unemployment and fertility in Italy: A time-series analysis, Demographic Research 34 (1), 1-38.

CHELLI F., ROSTI L. (2002), Age and gender differences in Italian workers' mobility, International Journal of Manpower 23 (4), 313-325.

CHERLIN A., CUMBERWORTH E., MORGAN S. P., WIMER C. (2013), The effects of the Great Recession on family structure and fertility, The Annals of the American Academy of Political and Social Science 650 (1), 214-231.

CHORIANOPOULOS I., PAGONIS T., KOUKOULAS S., DRYMONITI S. (2010), Planning, competitiveness and sprawl in the Mediterranean city: The case of Athens, Cities 27 (4), 249-259.

CHORIANOPOULOS I., TSILIMIGKAS G., KOUKOULAS S., BALATSOS T. (2014), The 
shift to competitiveness and a new phase of sprawl in the Mediterranean city: Enterprises guiding growth in Messoghia - Athens, Cities 39, 133-143.

COLEMAN D. (2006), Europe's demographic future: Determinants, dimensions, and challenges, Population and Development Review 32 (S1), 52-95.

COLEMAN D. A. (2008), New Europe, new Diversity, Population Studies 62 (1), 113120.

COPPI R., BOLASCO S. (1988), Multiway data analysis, North-Holland, Amsterdam. COUNCIL OF EUROPE (2001), Recent Demographic Developments in Europe, Council of Europe Publishing, Strasbourg.

CUADRADO-CIURANETA S., DURÀ-GUIMERÀ A., SALVATI L. (2017), Not only tourism: unravelling suburbanization, second-home expansion and "rural" sprawl in Catalonia, Spain, Urban Geography 38 (1), 66-89.

DELLADETSIMA P. M. (2006), The emerging property development pattern in Greece and its impact on spatial development, European Urban and Regional Studies 13 (3), 245-278.

DI FELICIANTONIO C., SALVATI L. (2015), 'Southern' alternatives of urban diffusion: Investigating settlement characteristics and socio-economic patterns in three Mediterranean regions, Tijdschrift voor Economische en Sociale Geografie 106 (4), 453-470.

DIJKSTRA L., GARCILAZO E., MCCANN P. (2015), The effects of the global financial crisis on European regions and cities, Journal of Economic Geography 15 (5), 935-949.

GAUTHIER A. H. (2007), The impact of family policies on fertility in industrialized countries: a review of the literature, Population Research and Policy Review 26 (3), 323-346.

GAVALAS V. S., RONTOS K., SALVATI L. (2014), Who becomes an unwed mother in Greece? Sociodemographic and geographical aspects of an emerging phenomenon, Population, Space and Place 20 (3), 250-263.

GKARTZIOS M. (2013), 'Leaving Athens': Narratives of counterurbanisation in times of crisis, Journal of Rural Studies 32, 158-167.

GKARTZIOS M., SCOTT K. (2015), A Cultural Panic in the Province? Counterurban Mobilities, Creativity, and Crisis in Greece, Population, Space and Place 21 (8), 843-855.

GOLDSTEIN J. R., KLUGE F. (2016), Demographic Pressures on European Unity, Population and Development Review 42 (2), 299-304.

GOLDSTEIN J., KREYENFELD M., JASILIONIENE A., ÖRSAL D. D. K. (2013), Fertility reactions to the "Great Recession" in Europe: Recent evidence from order-specific data, Demographic Research 29 (4), 85-104.

GOLDSTEIN J. R., SOBOTKA T., JASILIONIENE A. (2009), The end of "lowest-low" fertility?, Population and Development Review 35 (4), 663-699.

GOLINI A., GRIMACCIA E., RONDINELLA T., SQUILLANTE D. (2014), The Mediterranean: an unsustainable wall towards Europe, Italian Review of Economics, Demography and Statistics 68 (2), 7-20.

GRIGORIADIS E., SALVATI L. (2015), Recession In Action: Exploring The Spatial Divergence Of Percapita Income In Greece, Romanian Journal of Regional Science 9 (2), 6883.

HAASE A., KABISCH S., STEINFÜHRER A., BOUZAROVSKI S., HALL R., OGDEN P. (2010), Emergent spaces of reurbanisation: exploring the demographic dimension of inner-city residential change in a European setting, Population, Space and Place 16 (5), 443-463.

HOFMANN B., HOHMEYER K. (2013), Perceived economic uncertainty and fertility: evidence from a labor market reform, Journal of Marriage and Family 75 (2), 503-521.

HORTON R. (2009), The global financial crisis: an acute threat to health, Lancet 373 (9661), 355-356.

JOHNSON K. M., VOSS P. R., HAMMER R. B., FUGUITT G. V., MCNIVEN S. (2005), Temporal and spatial variation in age-specific net migration in the United States, Demography 42 (4), 791-812.

KABISCH N., HAASE D. (2011), Diversifying European agglomerations: evidence of urban population trends for the 21st century, Population, Space and Place 17 (3), 236-253. KALMIJN M., VAN TUBERGEN F. (2006), Ethnic intermarriage in the Netherlands: 
confirmations and refutations of accepted insights, European Journal of Population 22 (4), 371397.

KASIMIS C. (2008), Survival and expansion: migrants in Greek rural regions, Population, Space and Place 14 (6), 511-524.

KOHLER H.-P., BILLARI F. C., ORTEGA J. A. (2002), The emergence of lowest - low fertility in Europe during the 1990s, Population and Development Review 28 (4), 641-680.

KREYENFELD M., ANDERSSON G., PAILHÉ A. (2012), Economic Uncertainty and Family Dynamics in Europe: Introduction, Demographic Research 27 (28), 835-852.

KROLL F., KABISCH N. (2012), The Relation of Diverging Urban Growth Processes and Demographic Change along an Urban-Rural Gradient, Population, Space and Place 18 (3), 260-276.

KROONENBERG P. M. (2008), Applied Multiway Data Analysis, Wiley, London.

KULU H., BOYLE P. J., ANDERSSON G. (2009), High Suburban fertility: Evidence from Four Northern European Countries, Demographic Research 21 (31), 915-944.

LEE K. O., PAINTER G. (2013), What happens to household formation in a recession?, Journal of Urban Economics 76, 93-109.

LEE R. (2003), The demographic transition: three centuries of fundamental change, Journal of Economic Perspectives 17 (4), 167-190.

LEE R. D., REHER D. S. (2011), Introduction: The landscape of demographic transition and its aftermath, Population and Development Review 37 (s1), 1-7.

LESTHAEGHE R. J., NEIDERT L. (2006), The second demographic transition in the United States: Exception or textbook example?, Population and Development Review 32 (4), 669-698.

LESTHAEGHE R., VAN DE KAA D. J. (1986), Two demographic transitions?, Population: Growth and Decline, 9-24.

LIANOS T. P. (2001), Illegal migrants to Greece and their choice of destination, International Migration 39 (2), 3-28.

LIU L. (2005), Fertility trends in China's more developed urban districts: the case of four cities, Population, Space and Place 11 (5), 411-424.

MALOUTAS T. (2007), Segregation, social polarization and immigration in Athens during the 1990s: theoretical expectations and contextual difference, International Journal of Urban and Regional Research 31 (4), 733-758.

MARTÍN-GARCÍA T. (2013), Romulus and Remus or Just Neighbours?: A Study of Demographic Changes and Social Dynamics in Italy and Spain, Population Review 52 (1), 1 13.

MATTHEWS S., PARKER D. M. (2013), Progress in spatial demography, Demographic Research 28 (10), 271-312.

MCDONALD P. (2006), Low fertility and the state: The efficacy of policy, Population and Development Review 32 (3), 485-510.

MONTGOMERY M. R., CASTERLINE J. B. (1996), Social learning, social influence, and new models of fertility, Population and Development Review 22 (Supplement), 151-175.

MORELLI V. G., RONTOS K., SALVATI L. (2014), Between suburbanisation and re-urbanisation: revisiting the urban life cycle in a Mediterranean compact city, Urban Research \& Practice 7 (1), 74-88.

NEELS K., THEUNYNCK Z., WOOD J. (2013), Economic recession and first births in

Europe: recession-induced postponement and recuperation of fertility in 14 European countries between 1970 and 2005, International Journal of Public Health 58 (1), 43-55.

HOWELL F. M., PORTER J. R., MATTHEWS S. A. (eds.) (2016), Recapturing Space: New Middle-Range Theory in Spatial Demography, Springer, Berlin.

PILI S., GRIGORIADIS E., CARLUCCI M., CLEMENTE M., SALVATI L. (2017), Towards Sustainable Growth? A Multi-criteria Assessment of (Changing) Urban Forms, Ecological Indicators 76, 71-80.

PLANE D. A. (1993), Demographic Influences on Migration, Regional Studies 27 (4), 
375-383.

PROIETTI T. (2005), Convergence in Italian regional per-capita GDP, Applied Economics 37 (5), 497-506.

REES P., VAN DER GAAG N., DE BEER J., HEINS F. (2012), European regional populations: current trends, future pathways, and policy options, European Journal of Population 28 (4), 385-416.

REHER D. S. (2011), Economic and social implications of the Demographic transition, Population and Development Review 37 (s1), 11-33.

REMOUNDOU K., GKARTZIOS M., GARROD G. (2016), Conceptualizing Mobility in Times of Crisis: Towards Crisis-Led Counterurbanization?, Regional Studies 50 (10), 16631674.

RONTOS K. (2007), Prospects for a new family formation and for its impact on fertility: Some research evidences from Greece, Statistical Review 3 (1), 1-9.

RONTOS K. (2010), Demographic trends, young people's attitudes towards marriage and socio-economic changes related to family formation in Greece and in selected European Countries: A comparative analysis based on official and survey research data, International Journal of Criminology and Sociological Theory 3 (2), 543-562.

RONTOS K., GRIGORIADIS S., SATERIANO A., SYRMALI M., VAVOURAS I., SALVATI L. (2016), Lost in Protest, Found in Segregation: Divided Cities in the Light of the 2015 'Oki' Referendum in Greece, City, Culture and Society 7 (3), 139-148.

ROVOLIS A., TRAGAKI A. (2006), Ethnic characteristics and geographical distribution of immigrants in Greece, European Urban and Regional Studies 13 (2), 99-111.

SALVATI L., CARLUCCI M. (2017), Urban Growth, Population and Recession: Unveiling Multiple Spatial Patterns of Demographic Indicators in a Mediterranean City, Population, Space and Place 23 (8), e2079.

SALVATI L., MAVRAKIS A., SERRA P., CARLUCCI M. (2015), Lost in translation, found in entropy: An exploratory data analysis of latent growth factors in a Mediterranean city (1960-2010), Applied Geography 60, 107-119.

SALVATI L., MORELLI V. G. (2014), Unveiling Urban Sprawl in the Mediterranean Region: Towards a Latent Urban Transformation?, International Journal of Urban and Regional Research 38 (6), 1935-1953.

SALVATI L., SABBI A. (2014), Identifying urban diffusion in compact cities through a comparative multivariate procedure, The Annals of Regional Science 53 (2), 557-575.

SALVATI L., SATERIANO A., GRIGORIADIS E. (2016), Crisis and the City: Profiling Urban Growth under Economic Expansion and Stagnation, Letters in Spatial and Resource Sciences 9 (3), 329-342.

SANTOW G., BRACHER M. (2001), Deferment of the first birth and fluctuating fertility in Sweden, European Journal of Population 17 (4), 343-363.

SAYAS J. P. (2006), Urban sprawl in the periurban coastal zones of Athens, The Greek Review of Social Research 121 (C), 71-104.

SERRA P., VERA A., TULLA A. F., SALVATI L. (2014), Beyond urban-rural dichotomy: exploring socioeconomic and land-use processes of change in Spain (1991-2011), Applied Geography 55, 71-81.

SOBOTKA T., SKIRBEKK V., PHILIPOV D. (2011), Economic recession and fertility in the developed world, Population and Development Review 37 (2), 267-306.

SOBOTKA T., TOULEMON L. (2008), Overview Chapter 4: Changing family and partnership behaviour: common trends and persistent diversity across Europe, Demographic Research 19 (6), 85-138.

TAULBUT M., ROBINSON M. (2015), The chance to work in Britain: matching unemployed people to vacancies in good times and bad, Regional Studies 49 (12), 2070-2086. TRAGAKI A., BAGAVOS C. (2014), Male fertility in Greece: trends and differentials by educational level and employment status, Demographic Research 31 (6), 137-160.

VAN BAVEL J., REHER D. S. (2013), The baby boom and its causes: What we know 
and what we need to know, Population and Development Review 39 (2), 257-288.

VAN CRIEKINGEN M. (2010), 'Gentrifying the re-urbanisation debate', not vice versa: the uneven socio-spatial implications of changing transitions to adulthood in Brussels, Population, Space and Place 16 (5), 381-394.

VAN NIMWEGEN N. (2013), Population change in Europe: turning challenges into opportunities, Genus 69 (1), 103-125.

VIGNOLI D., DREFAHL S., DE SANTIS G. (2012), Whose job instability affects the likelihood of becoming a parent in Italy? A tale of two partners, Demographic Research 26 (2), 41-62.

VRACHNIS N., VLACHADIS N., ILIODROMITI Z., VLACHADI M., CREATSAS G. (2014), Greece's birth rates and the economic crisis, The Lancet 383 (9918), 692-693.

WALFORD N., KUREK S. (2016), Outworking of the Second Demographic Transition: National Trends and Regional Patterns of Fertility Change in Poland, and England and Wales 2002-2012, Population, Space and Place 22 (6), 508-525.

WATKINS S. C. (1990), From local to national communities: The transformation of demographic regimes in Western Europe, 1870-1960, Population and Development Review 16 (2), 241-272.

ZAMBON I., SERRA P., SAURI D., CARLUCCI M., SALVATI L. (2017), Beyond the 'Mediterranean City': Socioeconomic Disparities and Urban Sprawl in three Southern European Cities, Geographiska Annaler B 99 (3), 319-337.

ZAMBON I., BENEDETTI A., FERRARA C., SALVATI L. (2018), Soil Matters? A Multivariate Analysis of Socioeconomic Constraints to Urban Expansion in Mediterranean Europe, Ecological Economics 146, 173-183.

Initial submission: 08.12.2017

Revised submission: 23.02.2018

Final acceptance: 04.05.2018

Correspondence: Council for Agricultural Research and Economics (CREA), Research Centre for Forestry and Wood, Viale S. Margherita 80, I-52100 Arezzo, Italy; Department of Social and Economic Sciences, "Sapienza" University of Rome, Piazzale A. Moro 5, I-00185 Rome, Italy.

Email: luca.salvati@crea.gov.it 